Clin. Lab. Haem.

2005, 27, 135-138 CASE REPORT

\title{
A chronic myeloid leukemia-like syndrome case with del (12) (p12) in a Li-Fraumeni syndrome family
}

\author{
Ş. GURAN*, "Department of Medical Biology, Gülhane Military Medical Academy, Ankara, Turkey \\ C. BEYANt, †Department of Hematology, Gülhane Military Medical Academy, Ankara, Turkey \\ O. NEVRUZt, †Department of Molecular Biology and Genetics, Bilkent University, Ankara, Turkey \\ C. YAKICIER $\ddagger$ §Department of Medical Genetics, Gülhane Military Medical Academy, Ankara, Turkey \\ Y. TUNCA§
}

Summary Li-Fraumeni syndrome is a familial cancer syndrome characterized by different tumors and hereditary p53 mutations. Here, a chronic myeloid leukemia-like syndrome case in a Li-Fraumeni syndrome family with del (12) (p12) cytogenetic abnormality was presented. A hereditary p53 mutation (pro309ser) supported the Li-Fraumeni syndrome diagnosis in this family. This syndrome was characterized by the clonal myeloproliferative accumulation in bone marrow and peripheral blood with negative $b c r / a b l$ gene rearrangement finding. The etiology of this rare syndrome is still unclear. This is the only chronic myeloid leukemia-like syndrome case reported in a Li-Fraumeni syndrome family. Del (12)(p12) was observed in leukemias except chronic myeloid leukemia-like syndrome. The deletion in chromosome 12 p12 with hereditary $p 53$ mutation should have a critical role in chronic myeloid leukemia-like syndrome etiology in our case.

Keywords Li-Fraumeni syndrome, Philadelphia chromosome, bcr/abl translocation, chronic myeloid leukemia-like syndrome, $p 53$

\section{Introduction}

Li-Fraumeni syndrome is a hereditary cancer syndrome characterized by various tumors in childhood and adult time periods (Garber et al., 1991). Finding a hereditary p53 mutation supports the diagnosis (Malkin et al., 1990).

Chronic myeloid leukemia (CML) is a clonal myeloproliferative disorder resulting from oncogenic transformation of a bone marrow stem cell with a karyotypic hallmark named as Philadelphia $(\mathrm{Ph})$ chromosome because of bcr/ abl gene rearrangement (Deisseroth et al., 1993; Heim \& Mitelman, 1995). Patients with a chronic myeloid leukemia-like picture but lacking both $\mathrm{Ph}$ chromosome and $b c r$ rearrangement have been described as chronic myeloid leukemia-like syndrome (CML-like syndrome).

Accepted for publication 2 November 2004

Correspondence: Şefik Guran, İzmir Cad, Menekşe Sok, Moda İşhanı, A Blok Kat 3 No 131, Kizılay-Ankara, Turkey. Tel.: 9031230435 51; Fax: 9031241795 99; E-mail: sefguran@yahoo.com

(c) 2005 Blackwell Publishing Ltd
Such patients appear to have a distinct clinical course characterized by increasing leukocytosis, organomegaly, extramedullary infiltrates and bone marrow failure. The etiology of CML-like syndrome is still unclear (Kurzrock et al., 2001).

Here, a CML-like syndrome case with clonal del (12) (p12) cytogenetic abnormality was presented in a Li-Fraumeni syndrome family (a hereditary $p 53$ pro309ser mutation carrier). These two genetic abnormalities observed in our case may have an important role in CML-like syndrome progression.

\section{Case report}

A 45-year-old man came to our notice with dyspnea and fatigue symptoms and a high leukocyte count $\left(367 \times 10^{9} / \mathrm{l}\right)$. The family history revealed different tumors in an autosomal dominant inheritance pattern (Figure 1). Splenomegaly and pallor was observed in physical examination. The peripheral blood and bone marrow 


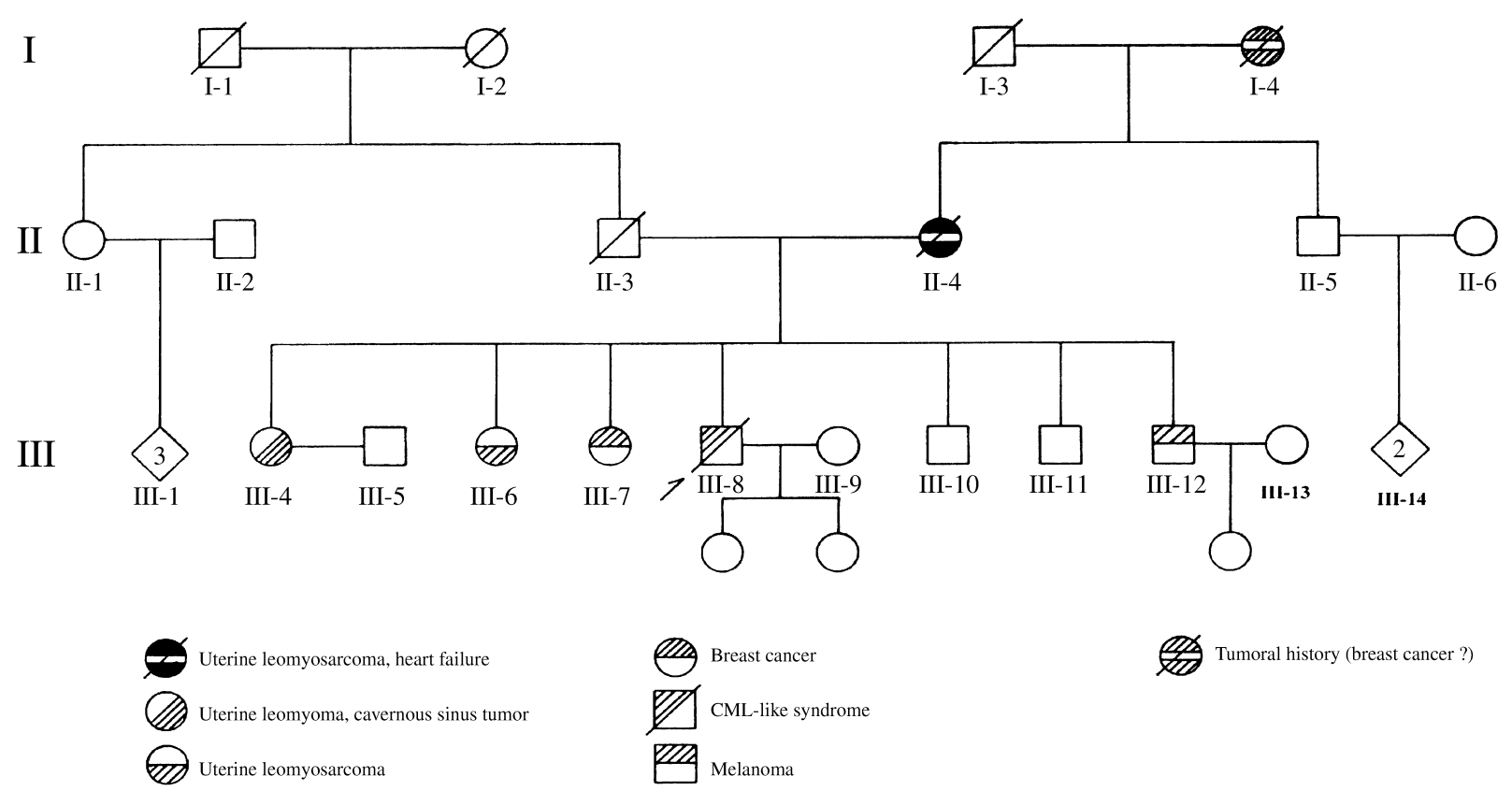

Figure 1. The pedigree of the family.

analyses revealed myeloid hyperplasia (the myeloblast ratio: $18.5 \%$; Figure 2). No $\mathrm{Ph}$ chromosome as a result of bcr/abl gene rearrangement was observed. Cytogenetic and molecular genetic analyses revealed del (12) (p12) and hereditary p53 pro309ser point mutation (Figures 3 and 4 ). As a result of these findings, the patient had CMLlike syndrome diagnosis as a Li-Fraumeni syndrome family member. Following chemotherapy, allogenic bone marrow transplantation was applied (from one of his siblings/III11). Eighteen months later, the patient died because of progression of the leukemia.

\section{Materials and methods}

\section{Cytogenetic and FISH analyses}

The cytogenetic analyses of bone marrow cells were studied after $1 \mathrm{~h}$ and $24 \mathrm{~h}$ of incubation. Methotrexate synchronization (high resolution) was also applied. Chromosomal preparations were GTG banded (Yunis, 1981). Metaphases were karyotyped according to the ISCN (Mitelman, 1995). Vyses LSI Bcr/abl ES Dual Color Translocation probe (VYSIS-3219102) was used for FISH analyses using the manufacturer's recommendations.

\section{P53 gene mutation analyses}

The DNA was isolated using standard procedures (Sambrook, Fritsch \& Maniatis, 1998). The hereditary p53 mutation was analyzed in exons 5 to 9 by using protocols

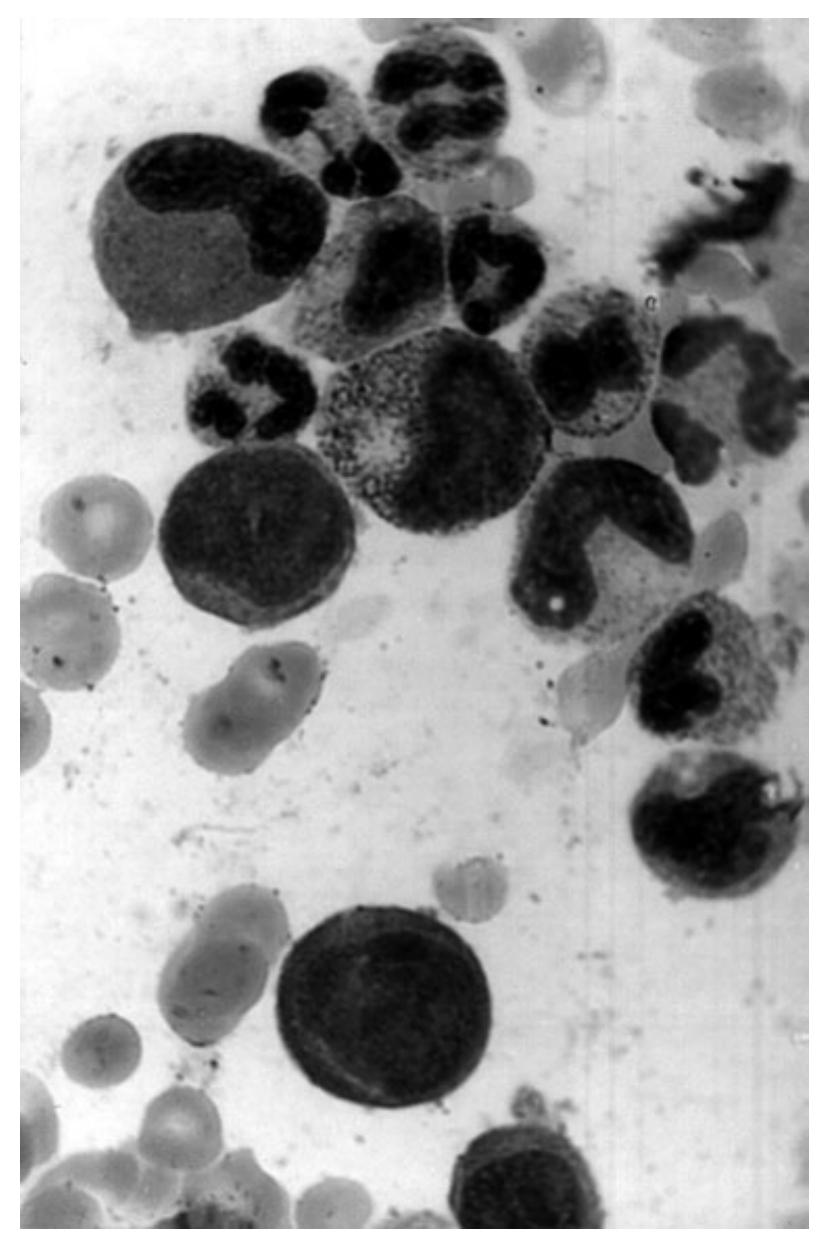

Figure 2. Bone marrow microscopy of CML case $(\times 1000$ magnification, May-Grunwald-Giemsa Dye).

(C) 2005 Blackwell Publishing Ltd, Clin. Lab. Haem., 27, 135-138 
Figure 3. The karyotype (a) represents 46, XY, del (12) (p12), and partial karyotype (b) represents del (12) (p12). (a)

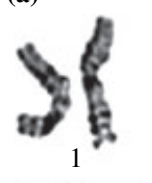

署

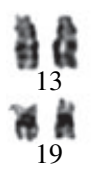

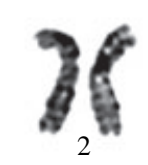

$\frac{9}{8}$

18

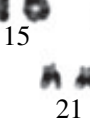

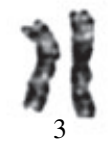
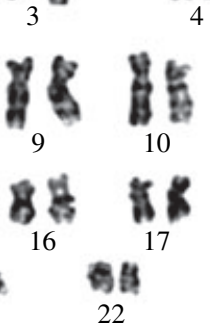

46, XY, del (12) (p12)
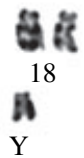

(b)
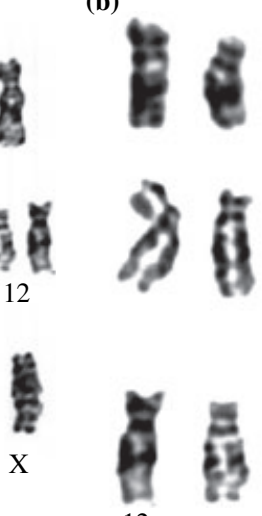

del (12) (p12)
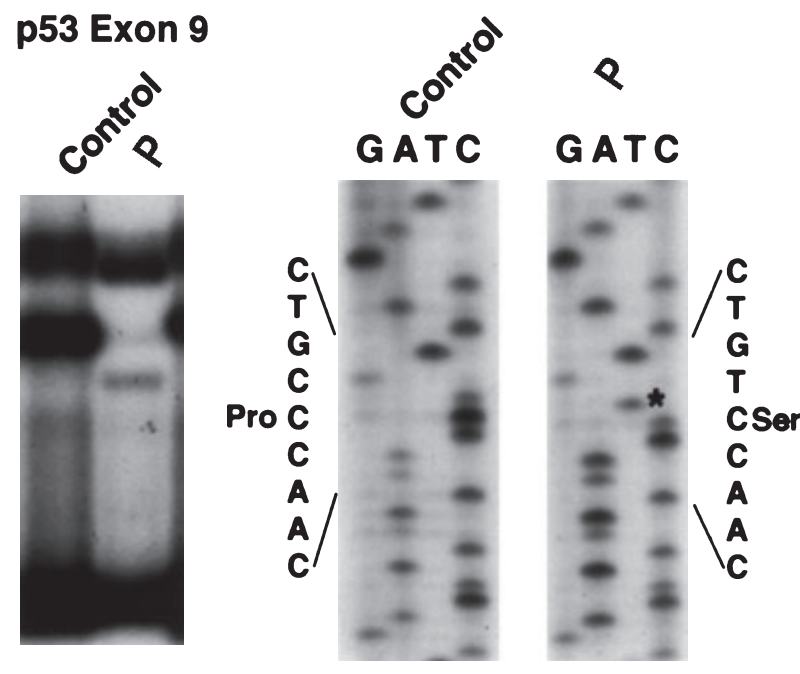

Figure 4. The single strand conformational polymorphism and sequence results of $p 53$ gene represent pro309ser mutation $(\mathrm{N}$, normal; $\mathrm{P}$, patient).

described by Guran and Tali (1999). LOH in the $p 53$ gene was analyzed by using the protocol of Barel et al. (1998). Two polymorphic loci in the p53 gene [restriction fragment length polymorphism (RFLP)-exon 4 and RFLP-intron 6] were used in $\mathrm{LOH}$ analyses.

\section{RNA preparation and RT-PCR}

The total RNA from bone marrow was isolated by using QiampRNA blood mini kit (Qiagen, Valencia, CA, USA), according to the manufacturer's recommendations. Reverse transcription was carried out with Omniscript$\mathrm{RT}$, following the manufacturer's protocol, with random hexamers primers. Following reverse transcription, $2 \mu \mathrm{l}$ (1/10) of each RT reaction was used for PCR using QIAGEN Taq DNA Polymerase and gene-specific primers, designed to span translocation regions as previously described (von Dongen et al., 1999).

\section{Results}

The cytogenetic analyses of the patient revealed $46, \mathrm{XY}$ [4], 46, XY del (12) (p12) [8], 46, XY, -15, del (7 q?), der (15) t (q15; ?) + mar [1] (Figure 3). t (9; 22) (q34; q11) (bcr/abl), t (8; 21) (q22; q22) (AML-1/MGT8), t (12,21) (p13; q22) (TEL/AML), t (15; 17) (q22; q21) (PML/RARA) and inv (16) (p13; q22) (CBFb/MHY 11) were negative in RT-PCR analyses. No brc/abl gene rearrangement finding was observed in FISH analyses. The DNA samples revealed a hereditary $p 53$ pro309ser point mutation in this family (Figure 4). No LOH of the $p 53$ gene was observed in DNA samples.

\section{Discussion}

The Li-Fraumeni syndrome was characterized by multiple malignant tumors (in childhood and adulthood) and hereditary $p 53$ gene mutations (Guran, Tunca \& Imirzalioğlu, 1999). Several tumors were observed in this family in an autosomal dominant inheritance pattern with the hereditary $p 53$ pro309ser mutation (Figure 1). P53 codon 309 mutations had been reported frequently in different tumors (Levine, MomAnd \& Finlay, 1991).

The $\mathrm{Ph}$ negative CML is a very rare clinical entity (Cortes et al., 1995). Poor prognosis had been reported in these cases (Martiat, Michaux \& Rodhain, 1991). Despite intensive chemotherapy and bone marrow transplantation, the patient died in a short time period. The genetic basis of CML-like syndrome is not well understood. Some chromosomal abnormalities (such as $+18,+21$, breakpoints at $5 \mathrm{q} 33$ and $8 \mathrm{p} 11$ ) were reported in the literature (Mcdonald et al., 1995), but their significance is still 
unclear. Here we observed a del (12) (p12) clonal cytogenetic abnormality. This cytogenetic abnormality was frequently reported in myelodysplastic syndrome, acute myeloid leukemia and acute lymphoblastic leukemia (L1 subtype with B or T cell lineage) (de Souza Fernandez et al., 2000; Adeyinka \& Dewald, 2003). Our case was the only example in CML-like syndrome with del (12) (p12) cytogenetic finding. The chromosome and gene alterations reported in our case should have an important role in disease progression in CML-like syndrome.

\section{References}

Adeyinka A. \& Dewald G.W. (2003) Cytogenetics of chronic myeloproliferative disorders and related myelodysplastic syndromes. Hematology/Oncology Clinics of North America 17, 1129-1149.

Barel D., Avigad S., Mor C., Fogel M., Cohen I.J. \& Zaizov R. (1998) A novel germ-line mutation in the non-coding region of the p53 gene in a Li-Fraumeni family. Cancer Genetics and Cytogenetics 103, 1-6.

Cortes J.E., Talpaz M., Beran M., O’Brien S.M., Rios M.B., Stass S. \& Kantarjian H.M. (1995) Philadelphia chromosome negative chronic myelogeneous leukemia with rearrangement of the breakpoint cluster region. Long term follow-up results. Cancer 75, 464-470.

Deisseroth B.A., Keating M.J., Andreeff M., Kantarjian H., Champlin R., Khouri I.F. \& Talpaz M. (1993) Chronic leukemias. In: Cancer, Principles and Practice of Oncology (eds V. De Vita, S. Hellman \& S.A. Rosenberg), 4th edn, pp. 1965-1983. JB Lippincott Co, Philadelphia.

von Dongen J.J., Macintyre E.A., Gabert J.A., Delabesse E., Rossi V., Saglio G., Gottardi E., Rambaldi A., Dotti G., Griesinger F., Parreira A., Gameiro P., Diaz M.G., Malec M., Langerak A.W., San Miguel J.F. \& Biondi A. (1999) Standardized RT-PCR analysis of fusion gene transcripts from chromosome aberrations in acute leukemia for detection of minimal residual disease. Report of the BIOMED-1 Concerted Action: investigation of minimal residual disease in acute leukemia. Leukemia 13, 1901-1928.
Garber J.E., Goldstein A.M., Kantor A.F., Dreyfus M.G., Fraumeni J.F. Jr \& Li F.P. (1991) Follow up study of twenty-four families with Li-Fraumeni syndrome. Cancer Research 51, 6094-6097.

Guran S., Tali E.T. (1999) P53 and p16 INK4A mutations during the progression of glomus tumor. Pathology Oncology Research 5, $41-45$.

Guran S., Tunca Y. \& Imirzalioğlu N. (1999) Hereditary TP53 codon 292 and somatic p16IN4A codon 94 mutations in a Li-Fraumeni syndrome family. Cancer Genetics and Cytogenetics 113, 145-151.

Heim S. \& Mitelman F. (1995) Cancer Cytogenetics, 2nd edn. Wiley Liss Inc, New York.

Kurzrock R., Bueso-Ramos C.E., Kantarjian H., Freireich E., Tucker S.L., Siciliano M., Pilat S. \& Talpaz M. (2001) BCR rearrangement - negative chronic myeloid leukemia revisited. Journal of Clinical Oncology 19, 2915-2926.

Levine A.J., MomAnd J. \& Finlay C.A. (1991) The p53 tumor suppressor gene. Nature 351, 453-456.

Malkin D., Li F.P., Strong L.C., Fraumeni J.F. Jr., Nelson C.E., Kim D.H., Kassel J., Gryka M.A., Bischoff F.Z., Tainsky M.A. et al. (1990) Germ line p53 mutations in a familial syndrome of breast cancer, sarcomas and other neoplasms. Science 250, 1233-1239.

Martiat P., Michaux J.L. \& Rodhain J. (1991) Philadelphia negative $(\mathrm{Ph}-)$ chronic myeloid leukemia (CML): comparison with $\mathrm{Ph}+\mathrm{CML}$ and chronic myelomonocytic leukemia. The Groupe de Francais de Cytogenetique Hematologique. Blood 78, 205-211.

Mcdonald D., Aguiar R.C., Mason P.J., Goldman J.M. \& Cross N.C. (1995) A new myeloproliferative disorder associated with chromosomal translocations involving 8p11: a review. Leukemia 9, 1628-1630.

Mitelman F. (1995) ISCN 1995: An International System for Human Cytogenetic Nomenclature 1995, 2nd edn. Karger, New York.

Sambrook J., Fritsch E.F. \& Maniatis T. (1998) Molecular Cloning, 2nd edn. Cold Spring Harbor Press, Baltimore.

de Souza Fernandez T., Ornellas M.H., Otero de Carvalho L., Tabak D. \& Abdelhay E. (2000) Chromosomal alterations associated with evolution from myelodysplastic syndrome to acute myeloid leukemia. Leukemia Research 24, 839-848.

Yunis J.J. (1981) New chromosome techniques in the study of human neoplasia. Human Pathology 12, 540-549. 